\title{
An Introductory Laboratory In Power Engineering Technology: A Systems Approach
}

\section{Dr. Matthew Turner, Purdue University, West Lafayette}

Dr. Matthew Turner is an Assistant Professor of ECET at Purdue University New Albany where he teaches courses in power systems and controls. Prior to joining the faculty at Purdue, Professor Turner worked as a researcher at the Conn Center for Renewable Energy Research in the area of power and energy systems, with a focus on smart grid implementation and computer modeling. Dr. Turner's current research concentrates on demand response technologies and the application of novel teaching and learning methods to power engineering education. 


\title{
An Introductory Laboratory in Power Engineering Technology: A Systems Approach
}

\author{
Matthew Turner
}

\begin{abstract}
This paper presents the design of a curriculum and the associated hardware for the laboratory component of an introductory power engineering technology course for sophomore students. The content was developed to implement a systems approach that uses the modern electric power network as an interconnected system to be designed, analyzed, and tested. The major hardware components of the electrical power system are studied and analyzed in individual laboratory experiments. By the end of the semester, students have integrated them together to create a working micro-grid.
\end{abstract}

\section{Introduction}

Despite being routinely identified by the National Academy of Engineering as the greatest engineering achievement of the $20^{\text {th }}$ century [1], academic support for and student enrollment in power engineering educational programs has not kept pace with other sub-disciplines of electrical engineering. This has resulted in a national need for well qualified power engineering and engineering technology graduates [2]-[4]. Additionally, the technical skills required of power engineers is constantly evolving and now include emerging topics such as smart grids, renewable and alternative energy sources, advanced energy efficiency and demand side management, and plug-in electric vehicles [3], as well the traditional skills necessary to maintain and operate the current aging infrastructure to continue to meet an ever increasing demand for electric energy[4]. As such, there has been a national call to develop new and innovative power engineering educational programs, and to create programs that "(1) promote the social importance of solving electric energy challenges and of delivering electricity economically, reliably, securely, and sustainably; (2) mankind education more interesting, such as by developing hands-on group projects across course levels to stimulate teamwork environments and synergy[2].

In response to this need, Purdue Polytechnic is developing an Energy and Power Engineering Technology Major (ENET), a concentration within Electrical Engineering Technology (EET) that focuses on electrical energy and power systems. As part of this degree program, a gateway course will be required for all EET sophomores that is designed to recruit into the ENET major, to serve as an introduction to AC systems analysis, and to explain electric energy and power systems in a systems context. This course was designed specifically with the IEEE mandate in mind, and great importance was placed on meeting the program characteristics described above. Therefore, the course content was chosen to emphasize the application of building renewable and efficient electric power systems. Topics such as renewable energy resources (wind, solar, and fuel cells), cleaner fossil fuel plants such as combined cycle, distributed generation, and demand response technologies were chosen to be emphasized in lieu of more traditional power engineering topics. Additionally, as hands-on-learning is a fundamental component of all coursework in Purdue Polytechnic, new laboratory activities were designed to support the course, focusing on the development of a familiarity with the major hardware components of, and the operation and control of, the electric power grid. This paper presents the laboratory content of the Modern Energy Systems course in which a functional micro-grid is constructed over the course of the semester, integrating both traditional power system technologies with emergent technologies such as renewable generation, smart grids, and demand side management.

\section{A Systems Approach}

Traditionally, two approaches to introductory electric power engineering courses have existed: (1) power systems analysis and (2) hybridized electric machines and electric power systems. The first method, as 
demonstrated in texts such as Stevenson[5], focuses on the development of system models for three phase components, the performance of network calculations, and the analysis of faulted systems. The second method, as demonstrated in texts such as Nasar [6], add the analysis of synchronous machines and electromechanical energy conversion to this, necessarily de-emphasizing a portion of the power systems analysis, usually fault calculations. Additional texts such as Cassazza [7] and VonMeirer [8], take a conceptual approach to the topic; reduced technical content with increased emphasis on qualitative understanding of system operation. For the development of Modern Energy Systems, it was decided to combine these methods: a qualitative explanation of system operation with a technical explanation of the major components of the grid. At all times, great emphasis is placed on putting any electrical component into context of the entire power system. More detailed analysis of power networks and AC machines is left to follow-on courses. It is hoped that this approach of developing a systems understanding of the power grid will attract more students to study the ENET degree.

Table 1 summarizes the content covered in Modern Energy Systems, as well as the associated laboratory curriculum. The course is divided into seven modules. The first, Fundamentals of Electric Energy Conversion is a general introduction to energy systems from a source and utilization perspective. It broadly deals with energy sources, units, conversion, and the utilization of electric energy via the electric grid. The second module, Fundamentals of AC power, covers the basic concepts necessary to understand and analyze three-phase AC systems. Module three, AC Generation, covers the process of electromechanical energy conversion via synchronous machines, synchronous machine electrical models, and the operation of all major categories of power plants. Module four, Electric Loads, covers the major load types, as well as load from a time perspective. Transmission and Distribution Lines, module five, covers electrical characteristics of conductors, common line models, and power flow over lines. This is followed by, module 6, a section on Power Transformers. Finally, the course concludes with module 7, a covering system operations, focusing on operation control of synchronous systems. Any remaining course time is used to introduce the concept and methods of power quality.

Table 1. Course Content and Associated Laboratory Activities for Modern Energy Systems.

\begin{tabular}{|c|c|}
\hline Major Course Topics & Lab Topic \\
\hline \multicolumn{2}{|c|}{ Fundamentals of Electric Energy Conversion } \\
\hline $\begin{array}{l}\text { - } \\
\text { - } \quad \text { Ulectric Energy Systems Overview } \\
\text { - Work, Energy, Forces and Sectors and Availability of Resources } \\
\text { - } \quad \text { Growth Rates } \\
\text { - } \quad \text { Basics of Electric Energy Conversion Processes } \\
\text { - Historical Development of U.S. Electric Power System, } \\
\text { - } \quad \text { Olectric Power System Equipment } \\
\text { One Diagrams and Reactance Diagrams }\end{array}$ & $\begin{array}{l}\text { Lab 1: Electric Energy Conversion } \\
\text { Efficiency } \\
\text { Lab 2: Hydro Electric Plant and } \\
\text { Substation Tour }\end{array}$ \\
\hline \multicolumn{2}{|l|}{ Fundamentals of AC Power } \\
\hline $\begin{array}{ll}\text { - } & \text { Resistance, Inductance, and Capacitance as Material Properties } \\
\text { - } & \text { Phasor Diagrams for Impedances } \\
\text { - } & \text { Single Phase AC Power } \\
\text { - } & \text { Three-Phase Power } \\
\text { - } & \text { Balanced The Configuration } \\
\end{array}$ & $\begin{array}{l}\text { Lab 3: Single Phase AC Power } \\
\text { Lab 4: Three Phase AC Power }\end{array}$ \\
\hline
\end{tabular}




\section{AC Generation}

- Electromechanical Energy Conversion and Synchronous Machine Operation

- Generator Terminal Characteristics

- Thermal Energy Conversion: Steam Processes

- Thermal Energy Conversion: Combustion Processes

- Mechanical Energy Conversion: Hydro

- Mechanical Energy Conversion: Wind

- Solar PV

Electric Loads

- $\quad$ Load Types and Load Models

- Load Profiles

Lab 5: Synchronous Generators

Lab 6: Wind Turbines

Lab 7: Solar PV and Inverters

- Electrical Characteristics of Conductors

- Short, Medium, and Long Line Models

- Power Flow Through A Transmission Line

Power Transformers

- Practical Transformer

- Three Phase Transformer

Lab 10: Transformer Characteristics

- Overview of Interconnected Power System

- Overview of Smart Grids and Distributed Generation

- Overview of Power Flow in Power System Networks

- Overview of Power Quality

Lab 11: Multiple Generator Systems

Lab 12: Smart Grids and Demand Side Management

\section{Laboratory Curriculum}

The laboratory curriculum implemented at Purdue University is based on the concept of a microgrid testbed. Such systems have been designed and developed for use in undergraduate teaching labs, utilizing either legacy electric machines equipment [9] or fully custom hardware [11]. Unlike the facilities previously described in the literature, which are constructed a priori and then analyzed by students, the approach taken in this paper is to have students build the system over the course of the semester. Through this approach, students are exposed to a number of traditional power system and electric machine experiments, as well as more modern topics. Overall, the goal is to aid students in understanding the basic structure and operation of the power grid: three phase systems, active and reactive power, electric machines, transmission and distribution lines and transformers, grid synchronization, and control of power flow.

\section{Lab 1: Electric Energy Conversion Efficiency}

The objective of Lab1 is to experimentally determine the efficiency of two electric energy transducers: an engine and alternator that convert gasoline into output electricity and a resistive coil that converts current into heat. These experiments introduce the students to the concept of energy conservation, the relationship between power and energy, energy and power unit conversions, and enable an understanding of the mechanisms and efficiencies of electric energy conversion processes.

In the first experiment, the class works as a group to design an experiment to calculate the heat rate of an electric generator. Through guided discussion, an experiment is developed in which students utilize the generator to combust a known quantity of fuel to deliver power to a load resistor, as shown in Figure 1. Input energy is calculated via the volume and energy density of the fuel. Output energy of the system is calculated via voltage and current measurements across a load resistor and elapsed time of combustion. The energy content of the fuel is then compared to the output energy delivered to the resistor, and an 
effective heat rate is calculated for the system. Students then compare the conversion efficiency of the system to tested average heat rates of modern electric power plants.

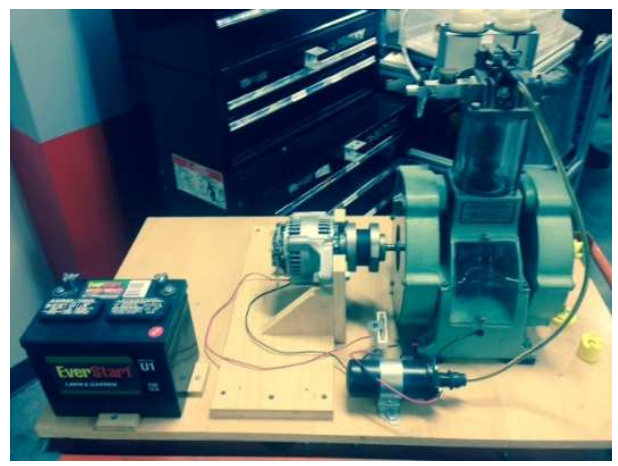

Figure 1. Ethanol Engine, DC Alternator, and Battery Load

In the second experiment, students work in teams of two to experimentally verify Joule's Law of Electric Heating and to determine the overall conversion efficiency of an electric heater. Containers of water are heated using an electric resistive heater. By measuring the heat energy required to raise the temperature of a container of water and comparing that results to the average electrical power dissipated by the resistive heater over time, the conversion efficiency of the heating system is determined. An experimental text fixture consisting of a resistive heater, analog temperature sensor, automated data acquisition system, and laboratory DMM is depicted in Figure 2

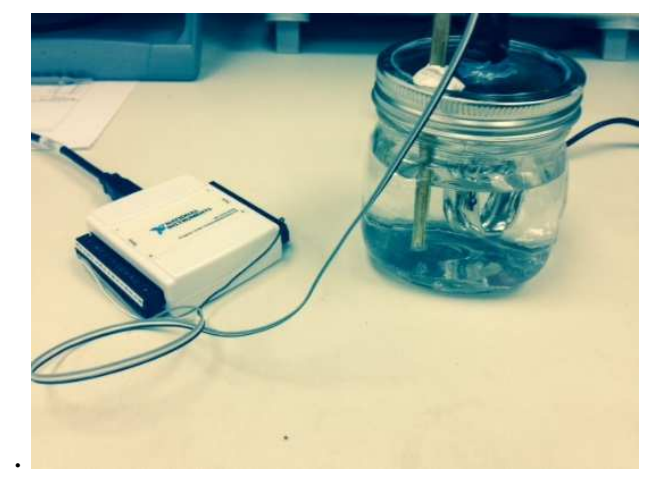

Figure 2. Joule Heating Experimental Set-up

\section{Lab 2: Hydro Electric Plant and Substation Tour}

The objective of Lab2 is to give students the opportunity to tour an electric power plant and associated substation (Figure 3). This field trip is designed to show the relevance and application of power engineering in an industrial setting. Student's tour the Louisville Gas and Electric's Ohio Falls Generating Station, a run-of-the-river hydro station with a head of $\sim 35$ feet, $8 \mathrm{GE}$ generators, and outputs voltage at $13.2 \mathrm{kV}$, with a total capacity of $\sim 100 \mathrm{MW}$. After the completion of the tour, students write field trip reports that summarize the operational aspects of the plant. 


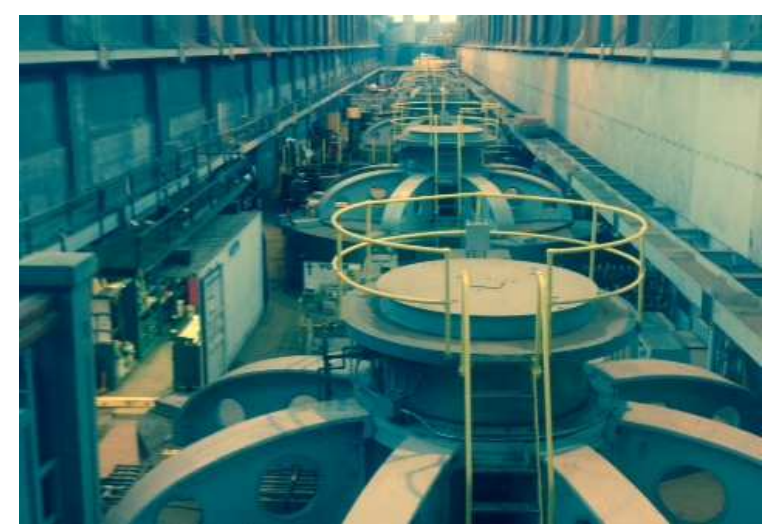

Figure 3. Hyrdo Turbines at Ohio Falls Generating Station.

\section{Lab 3: Single Phase AC Power}

The purpose of this assignment is to have students calculate the impedance, power, and power factor of a single phase load. Additionally, the impacts of low power factor are investigated. In part one of this experiment (Figure 4), students are provided one of three unknown loads: purely resistive, a capacitive (leading) load, or an inductive (lagging) load. The load is driven with a low voltage ac sine wave $\left(10 \mathrm{~V}_{\mathrm{RMS}}, 1 \mathrm{kHz}\right)$, and students utilize a two-channel oscilloscope to measure the voltages at nodes A1 and A2. Based on the voltage measurements and a known value for $\mathrm{R}_{\mathrm{T}}$, current, load impedance, apparent power, real power, and reactive power are calculated for all circuit elements, and conservation of power is demonstrated. Students draw power triangles and phasor diagrams for all circuit elements.

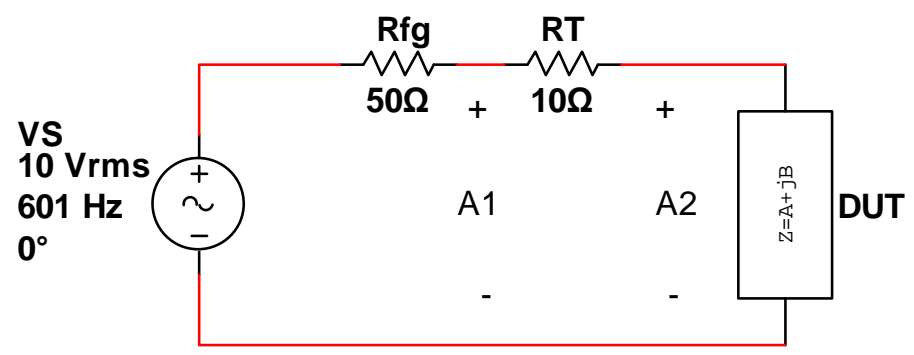

Figure 4. Single Phase AC Phase Measurement Circuit

In part 2 of Lab3, a 120V AC 1- $\varphi$ supply is connected to a lagging load consisting of an incandescent bulb in parallel with an inductive load. Students utilize panel meters to measure current and voltage amplitudes, as well as real power (Figure 5). Students calculate power factor angle via comparison of the measured voltage, current, and real power. A capacitive load is then connected to the system to perform power factor correction and students repeat their calculations. 


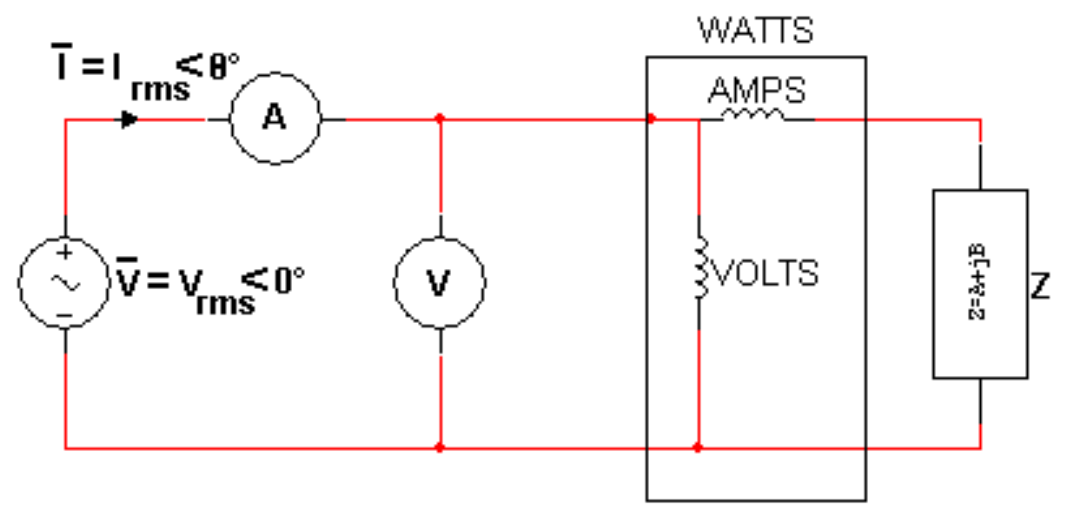

Figure 5. Single Phase AC Power Measurement Circuit

\section{Lab 4: Three Phase AC Power}

In Lab 4 students gain their first exposure to three-phase systems: Wye-Wye and Wye-Delta, as shown in Figure 6. Additionally, the voltage source is used to introduce the concept of the infinite bus. A balanced resistive load (60W incandescent bulbs) is placed on the system and students perform phase and line voltage/current measurements for both circuit configurations. An inductive load is added in parallel to the resistance, and students learn the two-wattmeter method, and calculate total real and reactive power draw from $\mathrm{P}_{\mathrm{T}}=\mathrm{P}_{\mathrm{AB}}+\mathrm{P}_{\mathrm{CB}}$ and $\mathrm{Q}_{\mathrm{T}}=\sqrt{3}\left(\mathrm{P}_{\mathrm{CB}}-\mathrm{P}_{\mathrm{AB}}\right)$.

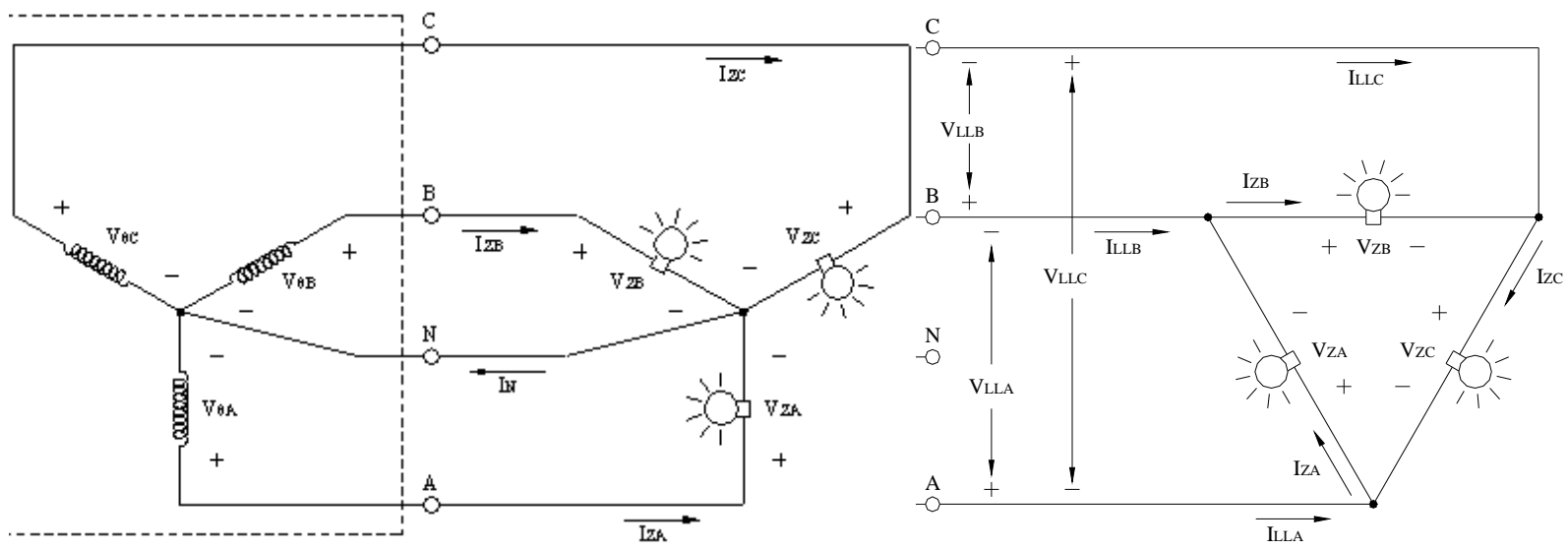

Figure 6. Three Phase AC Power Wye-Wye and Wye-Delta Test Circuits

\section{Lab 5: Synchronous Generators}

The objective of Lab 5 is to introduce students to the operational characteristics of a synchronous generator, to determine the generator equivalent circuit model, and to perform manual voltage regulation of a generator under various loading conditions. In part 1 of Lab 5, students determine the saturation characteristics of a synchronous generator and the generator equivalent model (Figure 7) by performing 1) an open circuit test to relate field current to open circuit armature voltage, 2) a short circuit test to relate field current to short-circuit armature current, and 3). a DC test to determine the armature resistance. Students use this data to develop and equivalent circuit model for the generator. 

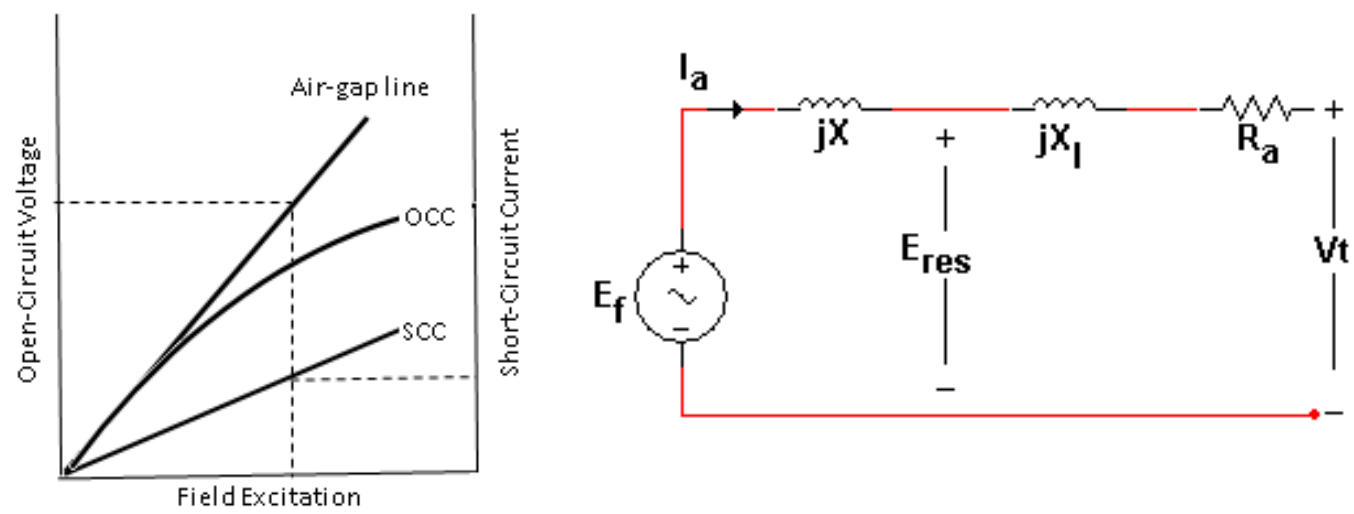

Figure 7. Synchronous Generator Open Circuit and Short Circuit Characteristics and Associated Equivalent Circuit

In Part 2 of Lab 5, students connect a three phase resistive load box to the output of the synchronous machine. Students adjust the field current to the generator to supply the load with the rated voltage, and measure field current, electrical frequency, mechanical rotational speed, phase current, and load voltage at different field current settings. Students use this data to determine the voltage regulation with a load attached the generator.

\section{Lab 6: Wind Turbines}

In Lab 6, the operation of a wind turbine generator is investigated. A scaled horizontal axis wind turbine (HAWT) is placed inside of a wind tunnel, and a power performance curve is generated by varying input wind speed and measuring output electrical power (Figure 8). Students identify the cut-in speed, rated speed, and cut-out speed of the wind turbine assembly.
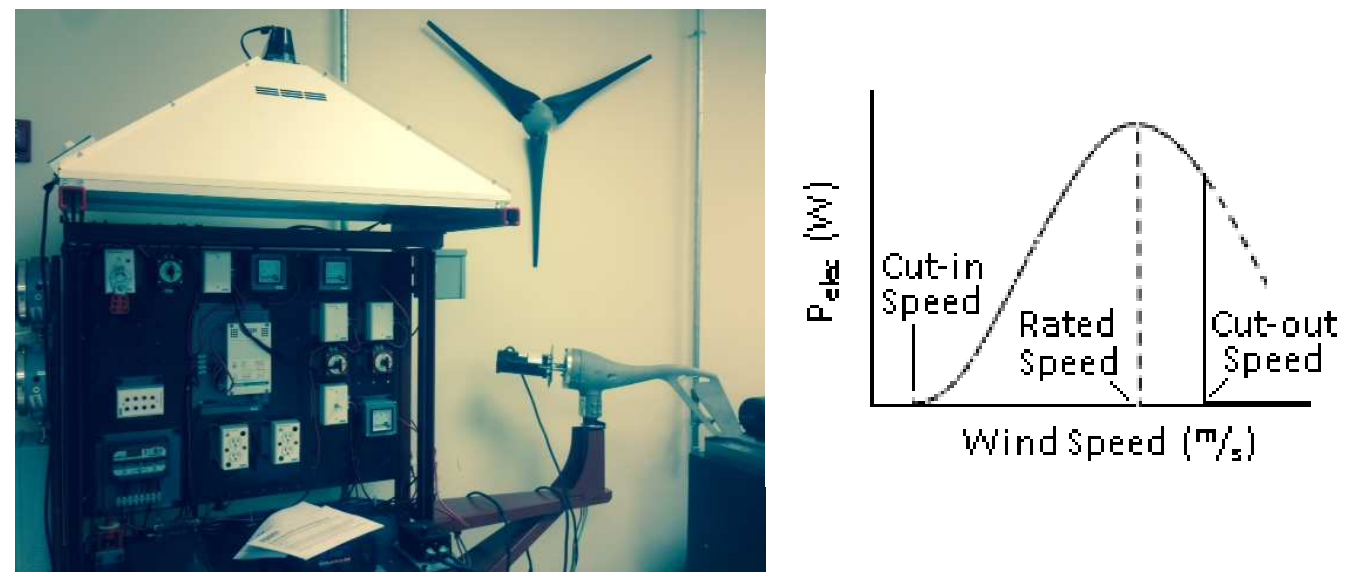

Figure 8. Wind/Solar Test Facility and Power Performance Curve.

In Part 2 of Lab 6, students experimentally determine the overall efficiency $(\eta)$ of the wind turbine as a functional of rotational speed. The generator is driven directly by a DC motor via direct coupling, and the output is connected to a purely resistive load. The rotational speed of the DC motor is adjusted using an adjustable DC power supply. Motor rotational speed is measured with an optical tachometer, and input 
and output voltage of the system are measured. Students calculate input power to the rotor and output power to the load, resulting in an efficiency as a function of RMP plot.

\section{Lab 7: Solar PV and Inverters}

The objective of Lab 7 is to examine the usage of solar PV panels to produce AC power. In part 1, students experimentally determine the current-voltage characteristics and maximum power point of a $12 \mathrm{Vdc} 85 \mathrm{~W}$ solar photo-voltaic panel placed into a sun simulator under constant illumination (Figure 8). The panel's open circuit voltage and short circuit current are then measured. The panel is then connected to a rheostat box, and the load resistance is varied from max-resistance to min resistance while current and voltage are recorded. Students plot the I-V data, and P-V data (Figure 9). The plots are then used to determine the maximum power point of the panel.

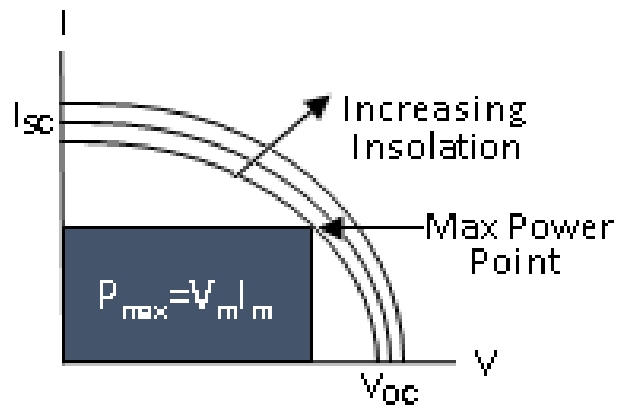

Figure 9. Solar Panel I-V Curve.

In part 2 of Lab 7, students operate the PV array at the maximum power point identified in part 1 . The effects of increasing solar insolation and panel tilt angle are then investigated. In both experiments, the load on the solar panel is held constant while either the solar insolation or tilt angle is changed. In both experiments, output power is plotted as a function of the input power. Students calculate conversion efficiency based on measured solar insolation values.

In part 3 of Lab 7, students test the performance of a sine-wave power inverter. Students calculate efficiency (Figure 10), voltage regulation, frequency regulation, and voltage distortion for a standard RL load with variable power factor.

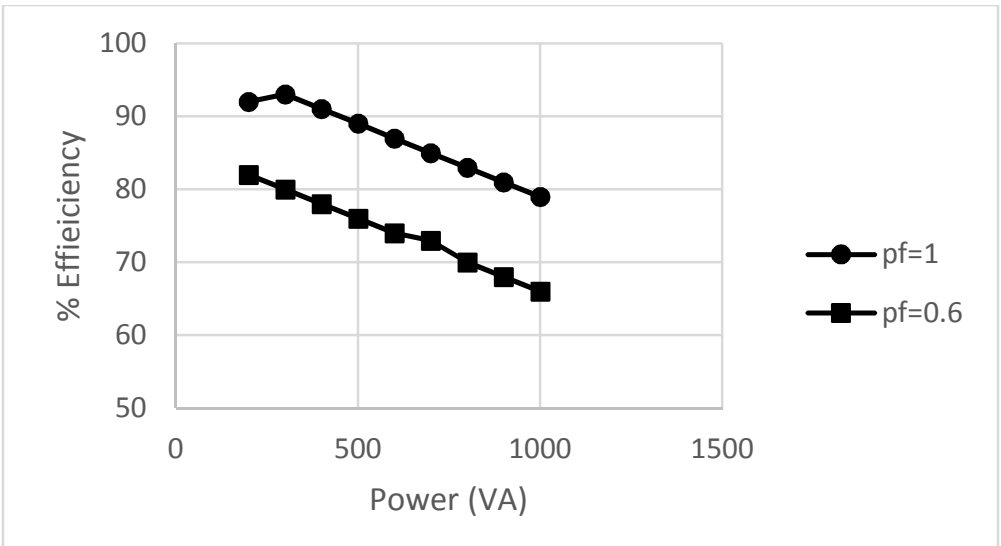

Figure 10. Efficiency Plot for Sine-Wave Inverters Under Lagging Loads.

Lab 8: AC Induction Motors and VFDs 
In this lab, students learn the characteristics of and how to operate an AC induction motor. In part 1, students characterize a 3-phase induction motor in terms of applied voltage, current, and power for both unloaded and loaded operating conditions. The Speed-torque characteristics are also determined. In this experiment, a three-phase squirrel cage induction motor is loaded using a Prony break and calibrated torque scale. A tachometer is used to measure output rotational velocity, and mechanical output power is calculated. Electrical input power is measured and efficiency as a function of load is plotted. Students also use output rotational velocity to calculate the slip of the induction motor as a function of load.

In part 2 of Lab 8, students are introduced to variable frequency operation of the induction motor. In this experiment students experimentally determine the relationship between motor speed and the frequency of the applied voltage. Plots are developed for voltage/power and torque as a function of applied frequency (Figure 11). Student identify the constant torque and constant power region of these plots.
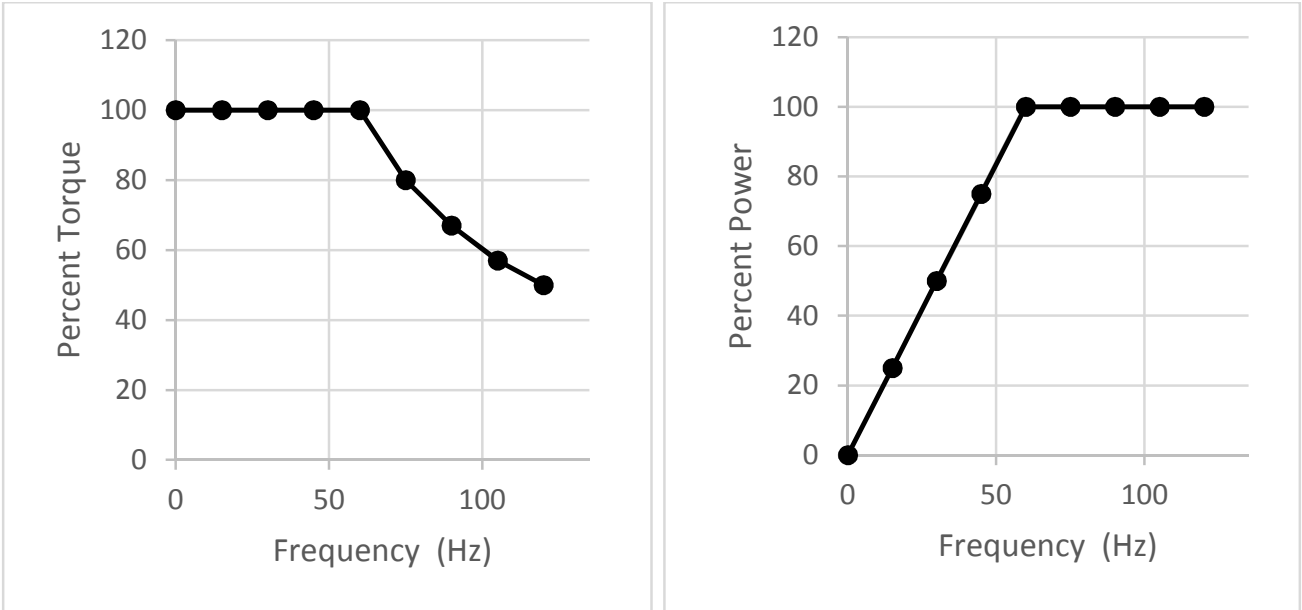

Figure 11. Torque and Power Curves for Variable Frequency Drive Operation of Induction Motor

\section{Lab 9: Voltage Drop in a Transmission Line and Power Factor Correction}

Lab 9 investigates the power flow over a three-phase medium length medium-voltage transmission line with known load. In part 1, based on a series reactance transmission line model (Figure 12), students calculate load-end voltage and phase shift. A three-phase transmission line module is connected to a three phase source and a wye connected RL load box. Students calculate phase shift and voltage regulation from measurements of line current, real power, sending end voltage, and receiving end voltage. Measurements are repeated for a range of power factors.

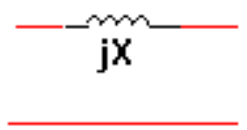

Figure 12. Medium Voltage, Medium Length Transmission Line Model.

In part 2 of Lab 9, students calculate the capacitive reactance necessary to perform power factor correction using shunt compensation for a pf of $0.65,0.85$, and 0.95 . Students calculate efficiency for each configuration. 


\section{Lab 10: Transformer Characteristics}

Lab 10 introduces students to power transformers. In part 1 of Lab 10, students perform a load test of a single phase transformer to determine efficiency and voltage regulation. Part 2 of Lab 10 introduces students to single-phase transformer characteristics in terms of a transformer equivalent circuit (Figure 13). The winding resistance is determined via a DC test, magnetization and core losses are tested under open-circuit conditions, and leakage reactance is tested under short-circuit conditions.
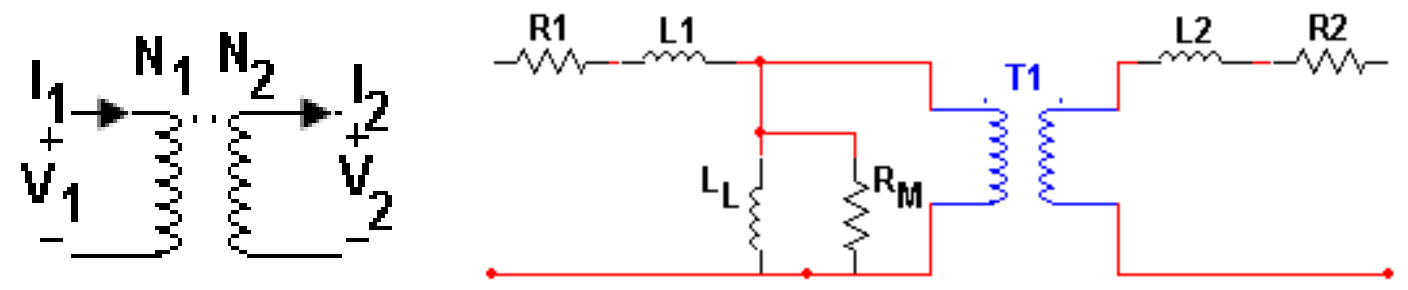

Figure 13. Practical Transformer Equivalent Model with Ideal Transformer.

In Part 3 of Lab 10, students provide power from an infinite bus to a load via a simple transmission system, as shown in Figure 14. Characteristics of the infinite bus, step-up transformer, transmission line, and step down transformer as determined in the previous labs are included to calculate power sourced by the generator, power receive by the load, and power dissipated in T1, LT, and T2. Overall efficiency of the system is also determined.

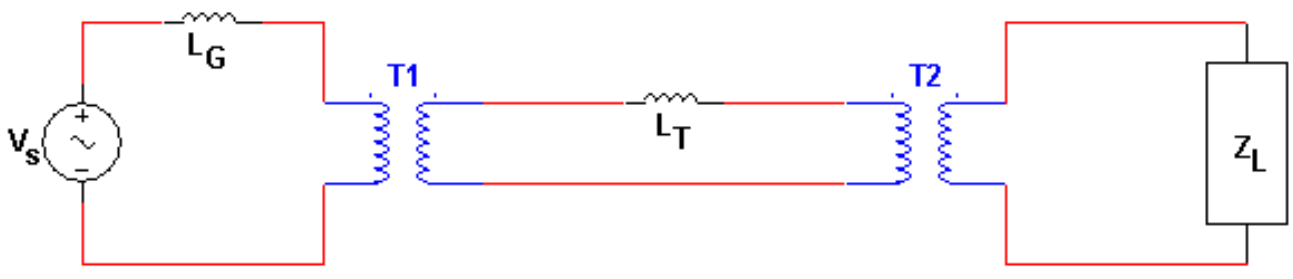

Figure 14. Simple Power System Test Circuit.

\section{Lab 11: Multiple Generator Systems}

The objective of Lab11 is to perform synchronization and electrical connection of a synchronous generator to an infinite bus and to calculate supply of real and reactive power, and to operate a 2 generator microgrid. A synchronous generator is driven via an adjustable DC machine, which provides the input torque to the system and is used to control real power. An external dc current supply is used to adjust the field current, and is used to control reactive power. The synchronous generator is connected to a threephase source (infinite bus) and three-phase adjustable RLC load via a three-phase contactor and synchroscope. The experimental setup is depicted in Figure 15. The load on the system is adjusted to operate the synchronous generator as under-excited, over-excited, and at unity power factor, with voltage and frequency control performed manually. For each case, students sketch an appropriate phasor diagram. 


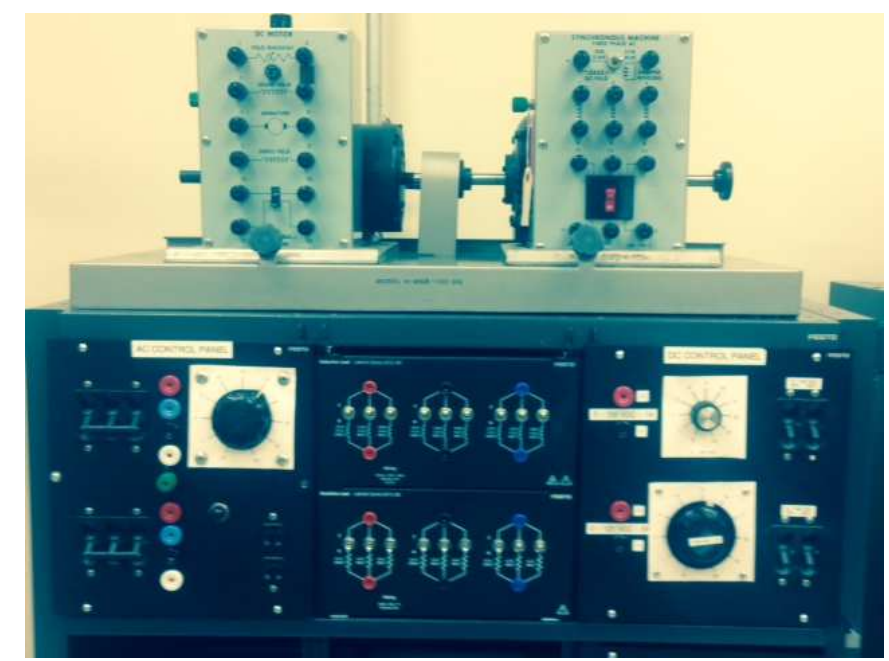

Figure 15. Microgrid for Multi-Generator Operation (Synchroscope not Shown).

\section{Lab 12: Smart Grids and Demand Side Management}

The purpose of Lab 12 is to demonstrate some common features of the smart grid: volt/var control and demands side management via direct load control. Students first construct the microgrid depicted in Figure 16, in which two loads are served via two generation sources. The generation source V1 is a synchronous machine driven by a DC motor. Source V2 is a programmable AC power supply that mimics an intermittent generation source such as wind or solar. The full output power of the combined sources is approximately 500W. Additionally, V1 and V2 are equipped with Automatic Generation Control, designed specifically for Lab 12. The generation sources serve 2 loads. Z1 is an RL load consisting of an induction motor connected to a Prony brake, representing an air conditioning load. Z2 is purely resistive and represents an uninterruptable load. Loads Z1 and Z2 are served by a transmission line LT1 that has a maximum rating of $>500 \mathrm{~W}$. At the load end, the step-down transformers have tapchanging settings, allowing the voltage at the load to be adjusted. Additionally, the distribution transformers are connected to reactive compensators.

In part 1 of Lab 12, the voltage tap settings are adjusted down from $120 \mathrm{~V}_{\mathrm{RMS}}$ to operate the distribution system at $114 \mathrm{~V}_{\mathrm{RMS}}$. The power factor of the system is then adjusted at the distribution transformer of the RL load. Students observe the change in current draw from the RL and R loads, and calculate energy savings achieved via both control methods. In part 2 of Lab 12, the output power of the intermittent generation source is reduced to mimic a shading event of the solar PV. Students compensate for the reduction in available power by reducing the load on the induction motor.

\section{Conclusion and Future Work}

This paper has presented the motivations, curricular design, and lab content for a sophomore level introductory power engineering course designed to stimulate enrollment into an Energy Engineering Technology major. The course implements a systems approach to demonstrate the common components of the electric power network, starting with basic energy conversion and ending with a functional microgrid. Through this method students are exposed to the components of electric energy systems, the analysis of power systems, and operation and control of power systems. This approach is unique in that it simultaneously exposes students to classic and emergent topics in power systems.

\section{References}


[1]. "Greatest Engineering Achievements of the 20 ${ }^{\text {th }}$ Century" Accessed February 1, 2016/ http://www.greatachievements.org/

[2]. National Science Foundation, 2008. National Science Foundation Workshop on the Future Power Engineering Workforce.

[3]. Institute of Electrical and Electronic Engineers, 2009. U.S. Power and Energy Engineering Workforce Collaborative.

[4]. Institute of Electrical and Electronic Engineers, 2013. Workforce of the Future.

[5]. Russell, B. D. (2010). Educating the Workforce for the Modern Electric Power System. BRIDGE, 35.

[6]. Grainger, John J., and William D. Stevenson. Power system analysis. Vol. 31. New York: McGraw-Hill, 1994.

[7]. Nasar, S. A. (1985). Electric Energy conversion and transmission. Macmillan Publishing Company.

[8]. Casazza, J., Casazza, J., \& Delea, F. (2003). Understanding electric power systems: an overview of the technology and the marketplace (Vol. 13). John Wiley \& Sons.

[9]. Von Meier, A. (2006). Electric power systems: a conceptual introduction. John Wiley \& Sons

[10]. Rasheduzzaman, M., Chowdhury, B. H., \& Bhaskara, S. (2014). Converting an Old Machines Lab Into a Functioning Power Network With a Microgrid for Education. Power Systems, IEEE Transactions on, 29(4), 1952-1962

[11]. Deese, A. S. (2013, July). Development of Smart Electric Power System (SEPS) Laboratory at The College of New Jersey. In Power and Energy Society General Meeting (PES), 2013 IEEE (pp. 1-5). IEEE 